\title{
Street orientation and side of the street greatly influence the microclimatic benefits street trees can provide in summer
}

\begin{abstract}
Maintaining human thermal comfort (HTC) is essential for pedestrians because people outside can be more susceptible to heat stress and heat stroke. Modification of street microclimates using tree canopy cover can provide important benefits to pedestrians, but how beneficial and under what circumstances is not clear. On sunny summer days, microclimatic measures were made in residential streets with low and high percentages of tree canopy cover in Melbourne, Australia. Streets with east-west (E-W) and streets with north-south (N-S) orientation were repeatedly measured for air temperature, relative humidity, wind speed, solar radiation, and mean radiant temperature on both sides of the street between early morning and midafternoon. Physiological equivalent temperature was estimated to indicate HTC throughout the day. In streets with high-percentage canopy cover, air temperature, relative humidity, solar radiation, and mean radiant temperature were significantly lower than in streets with low-percentage canopy cover. The reductions in air temperature under highpercentage canopy cover were greater for E-W streets $\left(2.1^{\circ} \mathrm{C}\right)$ than for $\mathrm{N}-\mathrm{S}$ streets $\left(0.9^{\circ} \mathrm{C}\right)$. For N-S streets, air temperature, mean radiant temperature, and solar radiation were greater on the east pavement in the early morning and greatest on the west pavement in the midafternoon. The midday thermal benefits are restricted to E-W streets, which are oriented in the same direction as the summer sun's zenith. High-percentage canopy cover reduced wind speeds but not enough to offset the other microclimate benefits. These findings can assist urban planners in designing street tree landscapes for optimal HTC in summer, especially in areas of high pedestrian density.
\end{abstract}

Keyword: Street orientation; Microclimatic; Street trees; Summer 